\title{
Active information sampling varies across the cardiac cycle
}

2

3

4

5

6

7

8

9

10

11

12

13

14

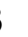

Stella Kunzendorf ${ }^{1,2,3^{\star}}$, Felix Klotzsche ${ }^{2,3}$, Mert Akbal $^{2,3}$, Arno Villringer $^{1,2,3,6}$, Sven Ohl ${ }^{4,5}$, \& Michael Gaebler $2,3,6$

Affiliations:

${ }^{1}$ Charité - Universitätsmedizin Berlin

${ }^{2}$ Dept. of Neurology, Max Planck Institute for Human Cognitive and Brain Sciences

${ }^{3}$ MindBrainBody Institute at Berlin School of Mind and Brain

${ }^{4}$ Bernstein Center of Computational Neuroscience, Berlin

${ }^{5}$ Humboldt-Universität zu Berlin

${ }^{6}$ Leipzig Research Centre for Civilization Diseases (LIFE), University Hospital Leipzig

*Corresponding author: stella.kunzendorf@charite.de, Max Planck Institute for Human Cognitive and Brain Sciences, Stephanstr. 1A, 04103 Leipzig, Germany, Phone: +49 (0) 30 / 20931729

Running title: Active information sampling and the heart

\section{Length and included material:}

5 figures; 1 table; 1 supplementary file (incl. 1 table, 2 figures).

Words: Abstract: 149; Intro: 1187; Methods: 2,764 (incl. caption); Results: 1,859 (incl. captions); Discussion: 2,028. 


\section{Abstract}

Perception and cognition oscillate with fluctuating bodily states. For example, visual processing has been shown to change with alternating cardiac phases. Here, we study the heartbeat's role for active information sampling-testing whether humans implicitly act upon their environment so that relevant signals appear during preferred cardiac phases. During the encoding period of a visual memory experiment, participants clicked through a set of emotional pictures to memorize them for a later recognition test. By selfpaced key press, they actively prompted the onset of shortly (100-ms) presented pictures. Simultaneously recorded electrocardiograms allowed us to analyse the self-initiated picture onsets relative to the heartbeat. We find that self-initiated picture onsets vary across the cardiac cycle, showing an increase during cardiac systole, while memory performance was not affected by the heartbeat. We conclude that active information sampling integrates heartrelated signals, thereby extending previous findings on the association between body-brain interactions and behaviour. 


\section{Introduction}

We perceive and act upon the world while our brain continuously integrates exteroceptive and interoceptive information, that is, information received from external (e.g., through vision and touch) and internal sources (e.g., through viscerosensation and proprioception), respectively (Barrett \& Simmons, 2015; Kleckner et al., 2017). Through the fine-tuned interplay of brain and body, we are able to react to changes in the external and the internal environment to maintain or restore our bodily integrity and well-being. Via feedback loops, the brain thereby receives afferent information about bodily states to regulate and adjust bodily activity accordingly (Craig, 2002; Critchley \& Harrison, 2013; Mayer, 2011; Saper, 2002). To fully capture the bi-directionality of brain-body interactions and their association with mental processes, it is essential to investigate if and how such afferent bodily information modulates our thoughts, feelings, and behaviour.

One approach to study bodily influences on cognition and behaviour exploits natural physiological fluctuations. Such fluctuations occur at multiple time scales-ranging from milliseconds to weeks (e.g., brain oscillations, heartbeats, the circadian rhythm, or the menstrual cycle)—and they dynamically interact with each other as well as with the environment (Glass, 2001). How such natural physiological variability is processed in the brain remains poorly understood. However, it has been shown that brain and beyond-brain organ systems (e.g., the cardiorespiratory or the gastrointestinal system) co-vary in their oscillatory activity (Fan et al., 2012; Luft \& Bhattacharya, 2015; Richter, Babo-Rebelo, Schwartz, \& Tallon-Baudry, 2017; Thayer, Åhs, Fredrikson, Sollers, \& Wager, 2012).

Particularly the heart, as a fundamental internal oscillator, has been the target of a growing body of research that investigates how cardiac fluctuations are integrated with the processing of external stimuli (Critchley \& Garfinkel, 2018). Cardiac activity occurs in a cycle of two phases: During diastole, the ventricles relax to be filled with blood; during systole, the ventricles contract and eject blood into the arteries, while visceral pathways send information about each heartbeat to the brain (Critchley \& Harrison, 2013). Such natural phasic changes of the cardiovascular state have been mainly associated with variations in perception: For 
sensory processing, which is typically measured with detection tasks or reaction time tasks, response to passively presented stimuli has been shown to be attenuated during early cardiac phases (i.e., during systole) or relatively enhanced at later time points in the cardiac cycle (i.e., at diastole) (Birren, Cardon, \& Phillips, 1963; Callaway \& Layne, 1964; Edwards, Ring, McIntyre, Carroll, \& Martin, 2007; Lacey \& Lacey, 1974; Mclntyre, Ring, Edwards, \& Carroll, 2008; Réquin \& Brouchon, 1964; Saari \& Pappas, 1976; Sandman, McCanne, Kaiser, \& Diamond, 1977; Wilkinson, Mclntyre, \& Edwards, 2013).

A growing number of more recent findings, however, suggests facilitated processing during systole, specifically for task- or context-relevant stimuli. While enhanced processing during systole was also reported for non-emotional visual stimuli (Pramme, Larra, Schächinger, \& Frings, 2014, 2016), an emotional specificity of this effect was observed when testing neutral stimuli vs. valenced stimuli like emotional faces-particularly for emotionally arousing fear or threat stimuli (Azevedo, Badoud, \& Tsakiris, 2018; Azevedo, Garfinkel, Critchley, \& Tsakiris, 2017; Garfinkel et al., 2014). Thus pointing towards an increase in emotional salience through interoceptive channels (Critchley \& Harrison, 2013), these findings correspond with evidence for preferential stimulus processing (e.g., enhanced perception and memory) fostered by states of general psychophysiological arousal (Cahill \& McGaugh, 1998; Mather, Clewett, Sakaki, \& Harley, 2016; Mather \& Sutherland, 2011; McGaugh, 2015; Tambini, Rimmele, Phelps, \& Davachi, 2017). At the same time, phasic cardiac modulation of stimulus processing has been associated with altered memory formation and retrieval (Fiacconi, Peter, Owais, \& Köhler, 2016; Garfinkel et al., 2013)—also in the context of respiratory oscillations (Zelano et al., 2016). Taken together, sensory processing is differentially modulated during early cardiac phases, indicating a selective processing benefit for relevant (e.g., emotionally arousing) stimuli, while other perceptual processes are attenuated (Garfinkel \& Critchley, 2016). This suggests that cardiac (or cardiorespiratory) fluctuations not only are an important target of efferent arousal regulation but contribute to afferent signalling of bodily arousal states to the brain (Critchley \& Harrison, 2013). 
However, these studies investigating cardiac influences on perception and cognition have only employed passive stimulus presentation, which ignores self-initiated action as a crucial dimension of sensory and particularly visual processing. Mediating our engagement with a visual scene, motor actions dynamically orchestrate incoming sensory data and thus strongly influence visual perception-selecting what information is preferentially processed (Benedetto, Spinelli, \& Morrone, 2016; Tomassini, Spinelli, Jacono, Sandini, \& Morrone, 2015). Sensorimotor coupling has also been linked to periodic attentional fluctuations (Hogendoorn, 2016; Morillon, Schroeder, \& Wyart, 2014). For example in the visual domain, saccadic eye movements are preceded by a shift of attention to the saccade target resulting in strongly improved visual performance (Deubel \& Schneider, 1996; Kowler, Anderson, Dosher, \& Blaser, 1995; Li, Barbot, \& Carrasco, 2016; Ohl, Kuper, \& Rolfs, 2017) and memory performance at the saccade target location (Hanning, Jonikaitis, Deubel, \& Szinte, 2016; Ohl \& Rolfs, 2017) with corresponding neural enhancement in early visual cortex (Merrikhi et al., 2017; Moore, Tolias, \& Schiller, 1998). There is sparse evidence that connects the heartbeat to general action generation and the few studies that investigated if movements are modulated across the cardiac cycle indicate that systole provides a facilitating time window for spontaneous motor activity-both in the somatomotor (Mets, Konttinen, \& Lyytinen, 2007) as well as in the oculomotor domain (Ohl, Wohltat, Kliegl, Pollatos, \& Engbert, 2016).

Based on findings of facilitated processing for visual stimuli (Azevedo et al., 2018, 2017; Garfinkel et al., 2014; Pramme et al., 2014, 2016) and increased oculomotor activity (Ohl et al., 2016) during early phases of the cardiac cycle, we here hypothesized that active information sampling (i.e., self-initiated action towards a visual stimulus) shows periodic variations with the phase of our heartbeat. To investigate perception and action within a comprehensive framework of mind-brain-body interactions, we here studied cardiac-related sensorimotor processing in a self-paced visual sampling paradigm, in which participants decide when to press a key to see a task-relevant visual stimulus. Extending studies that emphasize a selectivity of this effect for motivationally salient, passively presented stimuli (Azevedo et 
al., 2018, 2017; Garfinkel et al., 2014), we predicted that observers implicitly act upon a relevant visual stimulus such that it is received (and perceived) during preferred cardiac phases. More specifically, we hypothesized that visual sampling would be biased towards processing task-relevant pictures during systole.

We assessed the emotional specificity of cardiac-phase effects (Garfinkel et al., 2014; Garfinkel \& Critchley, 2016) by presenting negative, positive, and neutral pictures (cf. Methods). To further induce stimulus relevance, participants were instructed to memorize the pic-

130 tures during sampling and their recognition memory was tested after a delay of several minutes. This enabled us to also address the previously reported link between memory performance and the cardiac cycle: Based on the abovementioned systolic modulation of memory formation (Garfinkel et al., 2013), we expected recognition performance to be modulated by the cardiac timing of memory probes during encoding. Specifically, we hypothesized that memory performance for pictures encoded at different time points of the cardiac cycle is not equally distributed, but varies across the cardiac cycle.

\section{Methods}

Preregistration. The protocol and the hypotheses of our study were pre-registered prior to the data acquisition using the Open Science Framework (https://osf.io/5z8rx/).

141 Participants. 47 (23 female) healthy, young, right-handed subjects (age: $18-34$ years, $M=$ 25.8 years, SD $=4.31)$ with normal or corrected-to-normal vision participated in this study. Four subjects were excluded due to deviant cardiovascular parameters: two subjects with tachycardic mean resting heart rates (> $100 \mathrm{bpm}$ ), parallel to previous studies (Edwards, McIntyre, Carroll, Ring, \& Martin, 2002; Garfinkel et al., 2014; Wilkinson et al., 2013); one subject with hypertonic blood pressure $(171 / 89 \mathrm{mmHg})$, based on Tukey's (1977) criterion of 1.5 times the interquartile range (IQR) above the third quartile (Q3 $=122 \mathrm{mmHg}, I Q R=20.5$

$148 \mathrm{mmHg}$ ); one subject with numerous ventricular extrasystoles during the experimental period 149 (> 10 per minute). The sample size was based on previous cardiac cycle studies (mainly 150 Fiacconi et al., 2016): We aimed for a net sample size of 40 to enter the analyses (cf. 
151 https://osf.io/5z8rx/) expecting 10\% participant exclusions. Participants were recruited 152 through the ORSEE-based (Greiner, 2015) participant database of the Berlin School of Mind and Brain and received a monetary compensation of $9 € / \mathrm{h}$ for their participation. All participants were naïve regarding the purpose of the study and signed informed consent before participation. The study followed the Declaration of Helsinki and was approved by the Ethics Committee of the Department of Psychology at the Humboldt-Universität zu Berlin.

157 Setup and experimental task. (cf. Fig. 1a) Participants were seated in a dimly lit room in 158 front of a gamma-linearized 19-inch Cathode ray tube (CRT) monitor (Samsung Syncmaster 959NF, Suwong, Korea) with a refresh rate of $100 \mathrm{~Hz}$ and a spatial resolution of $1280 \times 1024$ pixels. Their head was positioned on a chin rest at a distance of $50 \mathrm{~cm}$ from the screen. The participants' task comprised two parts: During the encoding period, participants were asked to click through a picture set $(800 \times 600$ pixels $)$ in self-paced speed and to memorize the pictures for a subsequent memory test. By button press, they prompted the immediate onset of the next picture, which appeared for $100 \mathrm{~ms}$. In between self-chosen key presses (i.e., picture onsets), a central fixation cross was presented. After a break of five minutes, they completed the recognition period, during which they indicated for each picture whether or not they had seen it before. Here, pictures were passively presented for $100 \mathrm{~ms}$, followed by a centrally presented fixation cross until participants entered their recognition response ("old", "new") via key press.

170 Stimuli. The picture set consisted of 180 coloured photographs (60 pictures with positive, 60 171 with negative, and 60 with neutral content) of humans in various life situations, selected from 172 a collection of standardized and validated affective picture material (EmoPicS) (Wessa et al., 2010). For the index numbers of the selected photographs cf. Table S1 (Supplementary

174 Methods). To correct for potential stimulus-intrinsic influences on visual processing, the three picture sets were largely matched for physical image statistics (Wessa et al., 2010):

176 Contrast and visual complexity did not differ (all $p>.21$ ); positive images had significantly 177 higher luminance values than negative images $(t(118)=3.75, p<.001$, Cohen's $d=0.68)$, 178 while both did not differ from neutral images. In addition, two independent observers 
matched the three sets for more high-level stimulus features: (1) number of people shown, (2) number of images with social interactions, (3) number of images with close-ups, (4) number of images showing eye contact with the observer. Notably, positive and negative images were matched for (normative) arousal ratings and did not significantly differ $(t(78.6)=1.20, p$ $=.23$, Cohen's $d=0.22$ ). Stimuli were displayed using MATLAB version 7.8.0.347 (The MathWorks Inc., Natick, MA, USA) with the Psychophysics Toolbox 3 (Brainard, 1997; Kleiner et al., 2007; Pelli, 1997). For each participant, stimuli were randomly selected and presented in randomized order: For encoding, a subset of 120 pictures with 40 pictures of each picture valence (positive, neutral, negative) was sampled from the whole set of 180 . The second picture set, shown during the recognition period, consisted of the 60 yet unused pictures (20 per picture valence)-serving as distractors_as well as 60 memory probes (20 per picture valence) that were sampled from the encoded picture set.

ECG recording. ECG was recorded at $2048 \mathrm{~Hz}$ using an ActiveTwo AD amplifier (Biosemi, Amsterdam, Netherlands). Three electrodes were attached according to an adapted limb lead configuration at the right and left lower coastal arch as well as the left medial ankle. Participants were told that the ECG is to measure their general bodily state without mentioning details regarding the experimental conditions (Fiacconi et al., 2016). The ECG lead most clearly displaying the onset of ventricular depolarisation (lead II) was used for analysis.

Additional measures of inter-individual differences. Previous studies suggest that the influence of cardiac signals on perception and behaviour varies with interoceptive accuracy, that is, the ability to consciously perceive signals originating in the body (Dunn et al., 2010; Garfinkel et al., 2013). We determined inter-individual differences in interoceptive accuracy with a heartbeat perception task (Schandry, 1981), in which participants were asked to estimate the number of their heartbeats in five intervals of different length $(25,45,15,55$, and 35

204 s). As inter-individual differences in anxiety have been proposed to moderate the behavioural 205 effect of autonomic signalling (Garfinkel et al., 2014; Pollatos, Schandry, Auer, \& Kaufmann, 2007), we also acquired participants' trait anxiety using the State-Trait Anxiety Inventory 
207 (STAI-T; Laux, Glanzmann, Schaffner, \& Spielberger, 1981; Spielberger, Gorsuch, Lushene,

208 Vagg, \& Jacobs, 1983). Resting heart rate variability (HRV) measures inter-individual differ-

209 ences in brain-heart interaction and particularly in parasympathetic cardioregulation (Task

210 Force, 1996). HRV can be quantified through changes in the beat-to-beat intervals of the

211 ECG (Task Force, 1996). We calculated the root mean square of successive differences

212 (rMSSD) during the 7-minute baseline ECG.

213 Procedure. Upon arrival in the lab, participants were equipped with the ECG. Comfortably

214 seated, they were asked to relax for seven minutes and breathe normally. Then, blood pres-

215 sure was measured (twice, if elevated) using a standard sphygmomanometer (OMRON M8

216 Comfort). After a brief training session to familiarize participants with the task, they per-

217 formed the two experimental periods (i.e., encoding and recognition). During a 5-minute

218 break between the two parts, participants completed the Trait Anxiety Inventory (STAI-T)

219 (Laux et al., 1981; Spielberger et al., 1983). To assess subjective perception in our sample

220 and compare it to the EmoPicS' normative ratings, all 180 photos were rated after the recog-

221 nition period similarly to the original EmoPicS normative ratings (Wessa et al., 2010): "How

222 do you feel looking at the picture?" was answered for valence (1: sad - 9: happy) and arous-

223 al (1: calm - 9: excited) on a 9-level Likert-type scale. For each trial, both rating scales were

224 displayed successively, one above and one below each picture, followed by a 500-ms fixa-

225 tion cross (between trials). Finally, subjects performed the heartbeat perception task

226 (Schandry, 1981) that was presented acoustically.

227 Data analysis. The timing of behavioural responses was analysed relative to the heartbeats:

228 electrical events indicating the beginning of each cardiac cycle ( $R$ peaks) were extracted

229 from the ECG signal with Kubios 2.2 (Tarvainen, Niskanen, Lipponen, Ranta-aho, \&

230 Karjalainen, 2014, http://kubios.uef.fi/). Two complementary analytic approaches-circular

231 and binary analysis-were performed to exploit the oscillatory (repeating cycle of cardiac

232 events) as well as the phasic (two distinct cardiac phases: systole and diastole) nature of

233 cardiac activity, respectively.

234 Encoding period-cardiac modulation of self-paced visual sampling. 
Circular analysis: For the circular analysis, we computed the relative onset of each key press (prompting picture onset) within the cardiac cycle, which was indicated in the ECG as the interval between the previous and the following $\mathrm{R}$ peak (Fig. 1b). According to its relative timing within this R-R interval, radian values between 0 and $2 \pi$ were assigned to each stimulus (Ohl et al., 2016; Pikovsky, Rosenblum, \& Kurths, 2001; Schäfer, Rosenblum, Kurths, \& Abel, 1998). For each participant, we computed the mean of the circular distribution for the 120 picture onsets. In a second step, a mean vector of all participants was computed via vector addition of individual means divided by their number, showing the average self-paced picture onset in the cardiac cycle across the group, and weighted by its length (mean resultant length @) to reflect the spread of individual means around the circle. As a measure of concentration of circular data, @ was integrated in a subsequent Rayleigh test for uniformity (Pewsey, Neuhäuser, \& Ruxton, 2013): if @ gets sufficiently high to exceed a threshold value (i.e., the set of individual means is not spread evenly across the cardiac cycle), the data can be interpreted as too locally clustered to be consistent with a uniform distribution that served as null hypothesis (Pewsey et al., 2013). The code for individual and group-level circular analysis can be found on GitHub (https://github.com/SKunzendorf/0303_INCASI). Confidence intervals and significance were non-parametrically calculated through bootstrapping based on analyses from a previous study (Ohl et al., 2016): From the original pool of 43 participants, we drew a random bootstrap sample of 43 participants with replacement. For each participant in the bootstrap sample, we first computed a circular density (bandwidth $=20$ ) of picture onsets, and then computed the mean circular density across the 43 participants in the bootstrap sample. Confidence intervals (95\%) were determined as $2.5 \%$ and $97.5 \%$ percentiles from the distribution of mean circular densities obtained by repeating the bootstrap procedure 10000 times. Deviation from the circular uniform was considered as significant when the $95 \%$ confidence interval determined by the bootstrapping is outside the circular density of 260 a uniform distribution. 
and diastole (Fig. 1b). It needs to be noted that systolic phases vary inversely with heart rate (Fridericia, 1920; Lewis, Rittogers, Froester, \& Boudoulas, 1977; Lombard \& Cope, 1926; Wallace, Mitchell, Skinner, \& Sarnoff, 1963; Weissler, Harris, \& Schoenfield, 1968): Although the absolute length of systole decreases with a faster heartbeat, its proportionate share of the entire cardiac cycle increases. Between-subject variation of cardiac phase length (e.g., through differences in heart rate) supports the need to adapt analytical approaches in cardiac cycle studies. With the ECG waveform as physiological reference of cardiac activity, we did not use absolute systole and diastole lengths (e.g., defining systole as the $300 \mathrm{~ms}$ following an $\mathrm{R}$ peak) but computed participant-specific cardiac phases. Cardiac modulation of perception and cognition has often been attributed to baroreceptor signalling (e.g., Garfinkel \& Critchley, 2016; Lacey \& Lacey, 1974), which occurs in response to transient pressure rises (i.e., with the systolic upstroke) at each blood ejection (Angell James, 1971). In our approach, phases of high baroafferent feedback were approximated by determining each participant's systolic ejection phase (in the following referred to as "systole"). For the detailed binning procedure, the time ranges of individualized cardiac phases, and the association between heart rate and cardiac phase length cf. Supplementary Methods, Supplementary

Results, Fig. S1, and Fig. S2. The (self-paced) picture onsets were then assigned to the respective cardiac phase (i.e., individual systole or diastole). To take into account betweensubject differences in heart rate (and thus cardiac phase lengths), the sum of picture onsets per phase (as ratio of all 120 trials) was normalized to the proportion of the subject-specific phase length in the total cardiac cycle, resulting in a value of (picture onsets per cardiac phase / 120) / (individual cardiac phase length / individual mean R-R length) for each cardiac phase. With no cardiac effect, button presses (triggering picture onsets) would be randomly distributed across both cardiac phases. That is, the rate of systolic (diastolic) picture onsets should correspond to the proportion of systole (diastole) in the total R-R length, thereby resulting in a ratio of 1 . A ratio $>1$ thus reflects an over-proportional accumulation of picture onsets in the respective cardiac phase. In the group-level analysis, normalized systolic and diastolic ratios were tested against each other with a two-sided paired t-test. 


\section{Recognition period-cardiac modulation of recognition memory.}

Circular analysis: To relate memory performance in the recognition period and stimulus onset in the encoding period, we analysed-for each participant-the stimulus subset of memory probes (i.e., pictures in the recognition period that had already been shown during the encoding phase) with respect to their cardiac onset during encoding. Parallel to the circular analysis regarding visual sampling during encoding (see above), we computed the self-paced onset of memory probes during encoding across the participant's cardiac cycle (Fig. 1b). To correct for a possible bias due to self-paced memory probe distributions, three subjects with non-uniform circular distributions of memory probes (indicated by significant Rayleigh tests) were excluded from further analysis. At the group level, we then analysed circular distributions of onset times for memory probes that were correctly remembered (hits) or erroneously identified as new pictures (misses). To that aim, sets of individual mean onsets for hits and misses were tested against the circular uniform distribution using Rayleigh tests.

Binary analysis: The hypothesized association between cardiac phase and memory performance was further analysed by determining the stimulus' phasic timing during encoding, that is, whether it had been presented in individual systole or diastole (for detailed binning procedure cf. Supplementary Methods), relative to its recognition performance. To predict the binary recognition outcome (miss $=0$, hit $=1$ ), we computed general linear mixed regression models (GLMM) for binomial data, with subjects as random factor. The first model (m1) was fitted for the overall fixed effect of valence with the three levels of picture valence (positive, negative, neutral) contrast-coded against neutral picture valence as baseline condition. The second model (m2) included picture valence (negative-neutral, positive-neutral), cardiac phase (diastole $=0$, systole $=1$ ), and their interaction as fixed effects. Significance was obtained by likelihood ratio tests to compare the full model, which included the effect in question (i.e., valence, cardiac phase), with the reduced model, which did not include the effect in question (i.e., $\mathrm{m} 1$ vs. $\mathrm{m} 0$ and $\mathrm{m} 2$ vs. $\mathrm{m} 1$ ). NB: For $\mathrm{m} 1$, the data included only pictures encoded in individual systole or diastole (i.e., pictures encoded in non-defined cardiac intervals were excluded from analysis). An advantage of GLMMs (Jaeger, 2008) is that they 
319 can simultaneously test for random effects of subject and item (i.e., picture). To assess addi-

320 tional variance explained by individual pictures, we added picture as a random factor to our

321 models. For the regression analysis, we used the Ime4 package (Bates, Mächler, Bolker, \&

322 Walker, 2015) in the R Statistical Environment.

323 Exploratory analysis of visual sampling and recognition memory relative to inter-

324 individual differences. In an additional exploratory analysis, participants' individual (i.e.,

325 systolic and diastolic) ratios of self-paced picture onsets as well as their overall mean recog-

326 nition performance (i.e., the percentage of correctly recognised pictures) were correlated with

327 variables of inter-individual differences: Interoceptive accuracy (centred via z-transformation),

328 trait anxiety (centred via z-transformation), and resting heart rate variability/ rMSSD (log-

329 transformed to mitigate skewedness and centred to the mean). For measures of interocep-

330 tive accuracy, two participants with lacking information in the heartbeat perception task were

331 excluded from the analysis $(n=41)$.

332 Code availability. The code of our analysis, computed in the R Statistical Environment

333 (v3.4.3) with RStudio version 1.0.136 (RStudio Team, 2016) is available on GitHub

334 (https://github.com/SKunzendorf/0303_INCASI). Graphics were obtained with the circular

335 package (Agostinelli \& Lund, 2013) and the ggplot2 package (Wickham, 2009).

336 Data availability. The data that support the findings of this study are available on Github

337 (https://github.com/SKunzendorf/0303_INCASI). Data for preprocessing are available from

338 the corresponding author upon request. 
a

\section{Encoding}

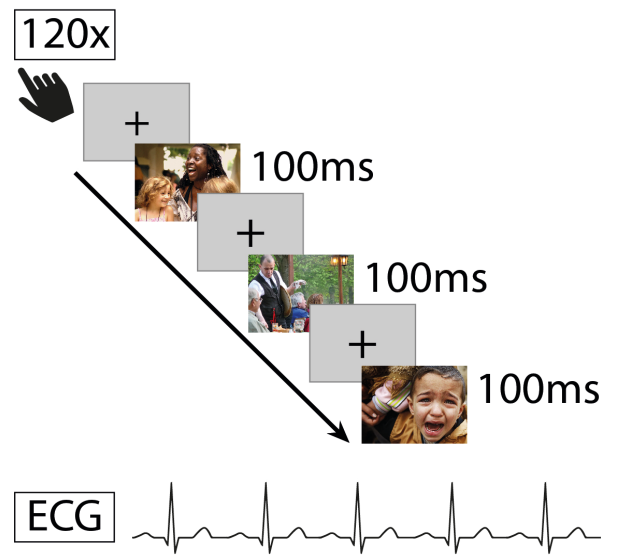

Recognition
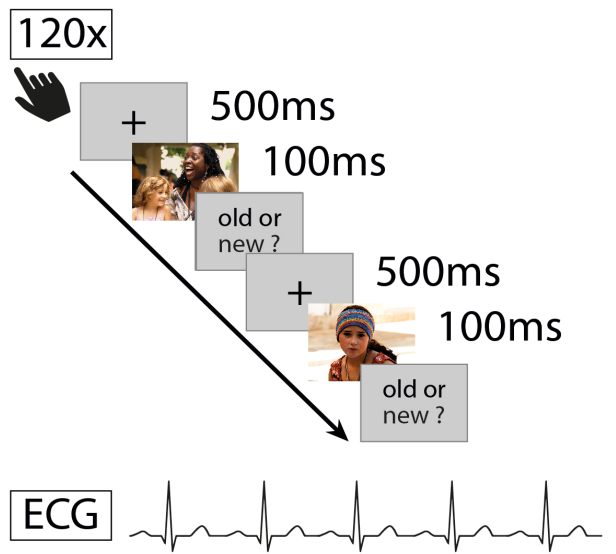

b Circular

Individual data

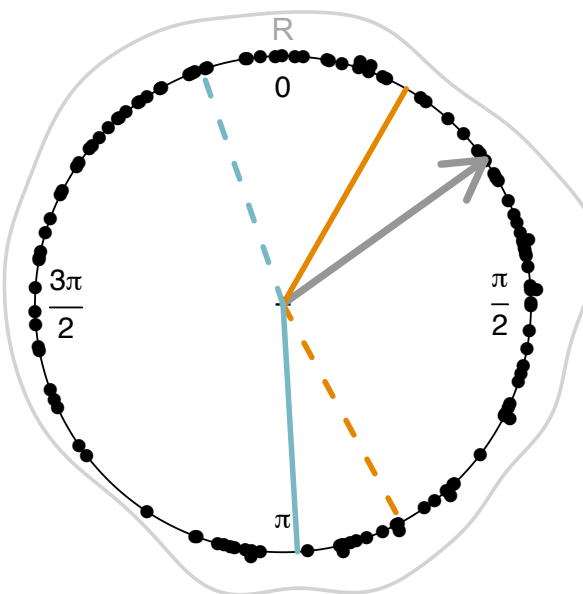

Binary

Individual ECG trace

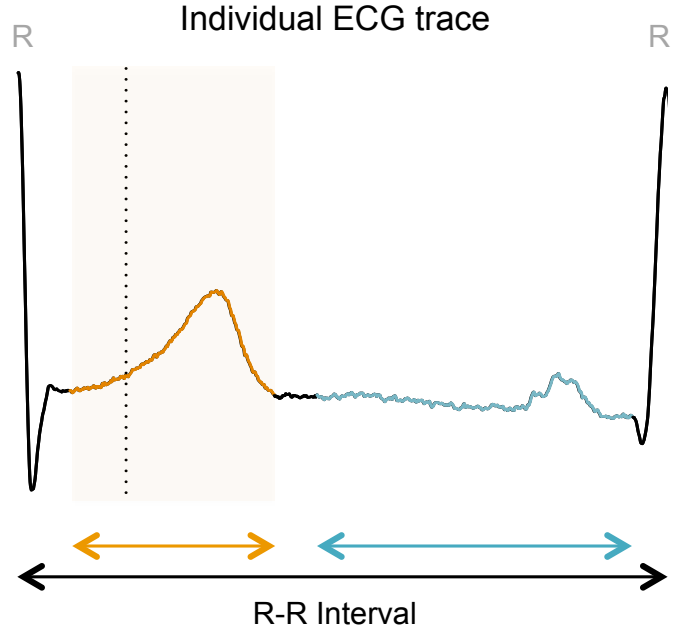

Figure 1. Experimental setup and data analysis. a, During encoding (top), participants prompted by button press the onset of the next picture, which could be positive, neutral, or negative. In the recognition period (bottom), they indicated for each picture (60 old, 60 new) whether or not they had seen it before. Simultaneous ECG was recorded to analyse behaviour relative to the cardiac cycle: $\mathbf{b}$, For circular analysis (top), values between 0 and $2 \pi$ were assigned to each stimulus onset (black dots), corresponding to its appearance within the cardiac cycle (from the previous to the next R peak in the ECG). Mean (grey arrow) and circular density (grey line) of stimulus onsets were calculated per subject. Individual cardiac phases from the binary analysis (see below) are visualised as circular segments (start: solid, end: dashed): systole (orange) and diastole (blue). For binary analysis (bottom), stimulus onsets (dashed line) were binned into participant-specific systole (orange) and diastole (blue) 
using a template approach (cf. Supplementary Methods, Supplementary Results, Fig. S1, and Fig.

S2).

\section{Results}

We tested whether self-paced visual sampling and visual memory encoding fluctuate across the cardiac cycle. Based on previous studies that demonstrated facilitated visual processing (Pramme et al., 2014, 2016) and increased oculomotor activity (Ohl et al., 2016) during the early phase of the cardiac cycle, we hypothesized that participants prefer to prompt a visual stimulus during early phases of the cardiac cycle. In addition, we hypothesized memory performance to be influenced by the cardiac time point of memory probes during encoding (Garfinkel et al., 2013).

Encoding: The distribution of self-paced picture onsets relative to the cardiac R-R interval showed an overall increase in early phases of the cardiac cycle $(\mathrm{M}=0.33 \pi, \mathrm{SD}=$ $0.52 \pi, \varrho=0.26$, cf. Fig. $2 a$ ). This observation was supported by inferential circular statistics indicating a non-significant trend that the self-paced key presses in the present experiment are unlikely to be uniformly distributed (Rayleigh test statistics $R_{0}=0.26, p=.053$ ). Of note, the same analysis with our preregistered sample size (i.e., the first 40 healthy subjects of $N=$ 43; cf. https://osf.io/5z8rx/) showed a significant deviation from a uniform distribution $\left(R_{0}=\right.$ $0.28, p=.039$ ), that is due to a significant increase in self-paced key presses in the interval from 0.24 to $0.44 \pi$ (Fig. 2a) as revealed by nonparametric bootstrapping (performed on the original participant pool, $\mathrm{N}=43$ ). Although this circular statistics can infer that the distribution of relative picture onsets deviates from a uniform distribution, it cannot pinpoint the transition from systole to diastole - particularly in the presence of varying heartbeat lengths, for which the same section of the circular distribution can be associated with different cardiac phases. puted the number of key presses during cardiac systole and diastole, normalised by the proportion of the systole vs. diastole in the whole cardiac cycle. We found a significantly larger $(t(42)=2.76, p=.009$, Cohen's $d=0.42)$ ratio of picture onsets in the systole $(M=1.05, S D$ 
$378=0.14)$ as compared to diastole $(M=0.97, S D=0.081)$, corroborating our finding of an in379 crease in self-paced visual sampling during cardiac systole (cf. Fig. 2b). Similar results were 380 obtained for the preregistered sample size $(n=40)$, showing a significantly larger $(\mathrm{t}(39)=$ $3812.70, p=.010$, Cohen's $d=0.43)$ systolic $(M=1.05, S D=0.14)$ than diastolic ratio $(M=$ $3820.97, \mathrm{SD}=0.079)$.

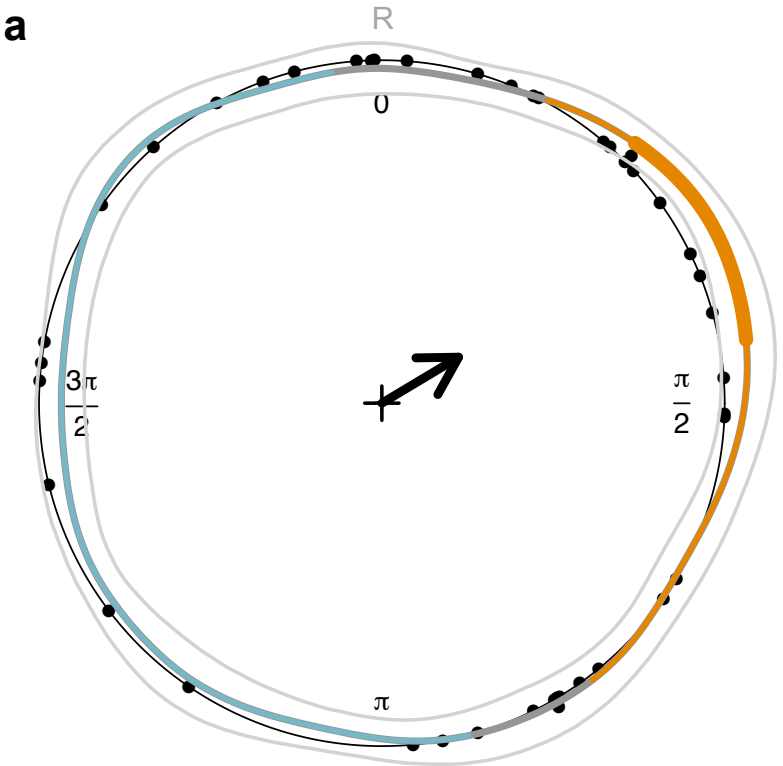

383 b

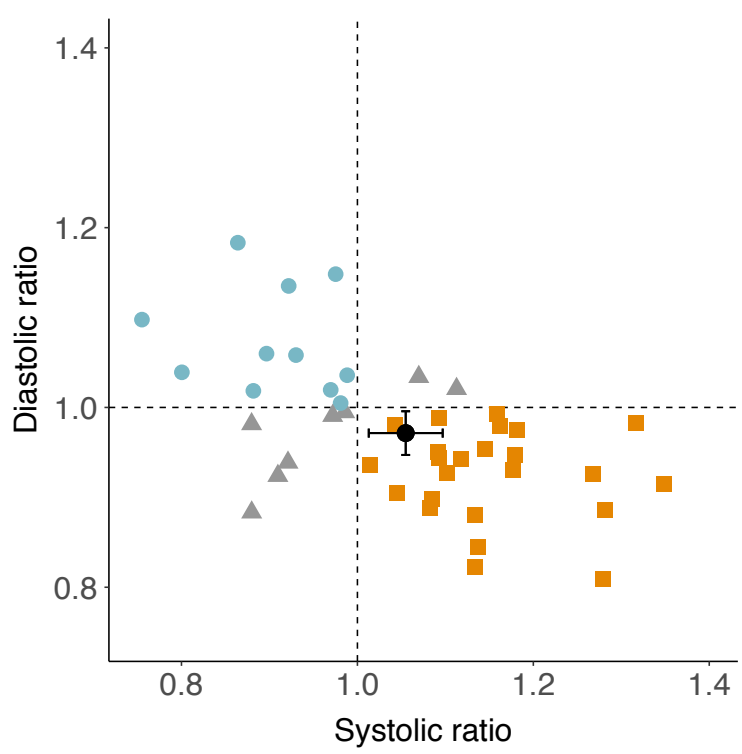

Figure 2. Circular and binary analysis of visual sampling relative to the heartbeat. a, Circular distribution of individual mean picture onsets (black dots, $N=43$ ) across the cardiac cycle (from $R$ peak to $\mathrm{R}$ peak). We observed a trend for increased self-prompted stimulus presentations (weighted overall mean as black arrow) in early phases of the cardiac cycle. Based on a bootstrapping procedure, we computed the mean circular density of picture onsets (middle thicker line), as well as a $95 \%$ confidence interval $(\mathrm{Cl}$, within inner and outer thin grey lines). Segments of the cardiac cycle are determined as statistically significant (thick orange segment) when the circular density significantly differs from the circular uniform (i.e., the lower bound of the $\mathrm{Cl}$ is outside of the black uniform circle). To relate segments of the cardiac cycle to the two cardiac phases (systole $=$ orange, diastole $=$ blue, nondefined $=$ grey), overall mean systole and diastole lengths were obtained, showing, that the significant density segment falls into systole. $\boldsymbol{b}$, Most subjects (24/43) preferred to prompt pictures during their systole (orange/square). Fewer subjects (11/43) chose to prompt them during their diastole (blue/dot) or did not show a preference in any of the two defined phases (8/43; grey/triangle). The phase-specific proportion of key presses (relative to all 120 trials) was normalized by the proportion of the cardiac phase (systole, diastole) in the entire $R-R$ interval. A ratio $>1$ thus indicates that the number of 
prompted picture onsets during systole or diastole exceeds the number that would be expected if they were uniformly distributed (resulting in a ratio $=1$, dashed line). The group-level mean (black dot with standard error bars) shows an over-proportional accumulation of picture onsets during individual systole relative to individual diastole. memory processing: In a circular analysis, we tested whether the distribution of onset times during stimulus encoding differed for pictures that were correctly remembered (hits) or erroneously identified as new pictures (misses). Overall, picture onset times during the encoding period did not significantly deviate from a uniform distribution over the cardiac cycle for hits $\left(R_{0}=0.20, p=.21\right)$ and misses $\left(R_{0}=0.16, p=.36\right)$.

We further investigated the influence of cardiac phase (systole, diastole) and picture valence on recognition memory. The results of the GLMM (cf. Table 1) with contrast-coded

412 picture valence $(\mathrm{m} 1)$, that is, negative-neutral and positive-neutral, showed a significant memory benefit for negative vs. neutral and for positive vs. neutral stimuli. More specifically, memory performance for negative pictures $(M=0.80, S D=0.13)$ and for positive pictures $(M$

$415=0.78, S D=0.16)$ significantly exceeded memory performance for neutral pictures $(\mathrm{M}=$ $4160.73, S D=0.18$ ). Comparison of $\mathrm{m} 1$ against the null model (without the fixed effect of va417 lence) showed that valence significantly increased the model fit. Critically, adding cardiac phase (i.e., systole, diastole) to the model (m2) did not improve the model fit (cf. Table 1): Neither phase nor its interaction with picture valence significantly accounted for variation in recognition memory. Compared to $\mathrm{m} 1$, cardiac phase did not significantly improve the model

421 fit. Adding picture as additional random effect only slightly changed parameter estimates but, 422 critically, did not account for additional variance in the association between memory perfor423 mance and the cardiac cycle (detailed results not reported).

a.

m1 ( picture valence)
Coefficient
SE

0.15
Z-Value

7.71
P-Value

$<.001$ 


\begin{tabular}{|c|c|c|c|c|c|c|}
\hline \multicolumn{3}{|c|}{ negative vs. neutral (neg-neu) } & 0.37 & 0.12 & 3.11 & .002 \\
\hline \multicolumn{3}{|c|}{ positive vs. neutral (pos-neu) } & 0.29 & 0.12 & 2.43 & .015 \\
\hline \multicolumn{7}{|c|}{ m2 ( picture valence $X$ cardiac phase) } \\
\hline \multicolumn{3}{|c|}{ Intercept } & 1.24 & 0.17 & 7.14 & $<.001$ \\
\hline \multicolumn{3}{|c|}{ cardiac phase $(0=$ diastole, $1=$ systole $)$} & -0.17 & 0.19 & -0.89 & .37 \\
\hline \multicolumn{3}{|c|}{ phase $X$ neg-neu } & 0.30 & 0.27 & 1.11 & .27 \\
\hline \multicolumn{3}{|c|}{ phase $X$ pos-neu } & 0.16 & 0.27 & 0.61 & .54 \\
\hline \multirow[t]{2}{*}{ b. } & & Fitting & & \multicolumn{3}{|c|}{ Likelihood Ratio Tests } \\
\hline & AIC & BIC & LogLikelihood & Chi-Square & Df & P-value \\
\hline m1 & 2626 & 2650 & -1309 & 10.71 & 2 & .005 \\
\hline $\mathrm{m} 2$ & 2171 & 2211 & -1079 & 1.24 & 3 & .74 \\
\hline
\end{tabular}

Table 1. a, General linear mixed model $($ GLMM) with recognition memory $($ hit $=1$, miss $=0)$ relative to picture valence (negative-neutral, positive-neutral) $(\mathrm{m} 1=$ memory $\sim$ picture valence $+(1 \mid \mathrm{vp})$ ), cardiac phase, and their interaction $(\mathrm{m} 2=$ memory $\sim$ picture valence $X$ cardiac phase $+(1 \mid v p))$. Valenced pictures (negative and positive) showed a significant memory benefit compared to neutral pictures. Neither cardiac phase nor its interaction with picture valence significantly accounted for variation in visual memory performance. $\boldsymbol{b}$, Likelihood ratio tests of $\mathrm{m} 1$ and $\mathrm{m} 2$ against the reduced model (i.e., $\mathrm{m} 0$ and $\mathrm{m} 1$, respectively) show that picture valence significantly increased the model fit while cardiac phase did not account for variation in memory performance.

Beyond our preregistered hypotheses, additional results were obtained by further exploratory analyses.

Systole-associated visual sampling and inter-individual differences. Individual systolic ratios of self-paced picture onsets were neither significantly correlated with interindividual differences in interoceptive accuracy $(r(39)=-.16, p=.32)$ nor in heart rate variability (i.e., resting rMSSD; $r(41)=.064, p=.69$ ). There was a non-significant (and not hypothesized) trend (Fig. 3b) for individual systolic ratios to increase with higher trait anxiety $(r(41)=.29, p=.062)$. Neither interoceptive accuracy $(r(39)=.25, p=.11)$ nor trait anxiety $(r(41)=-.21, p=.17)$ nor heart rate variability $(r(41)=.16, p=.32)$ significantly modulated individual diastolic ratios of picture onsets (Fig. 3). 

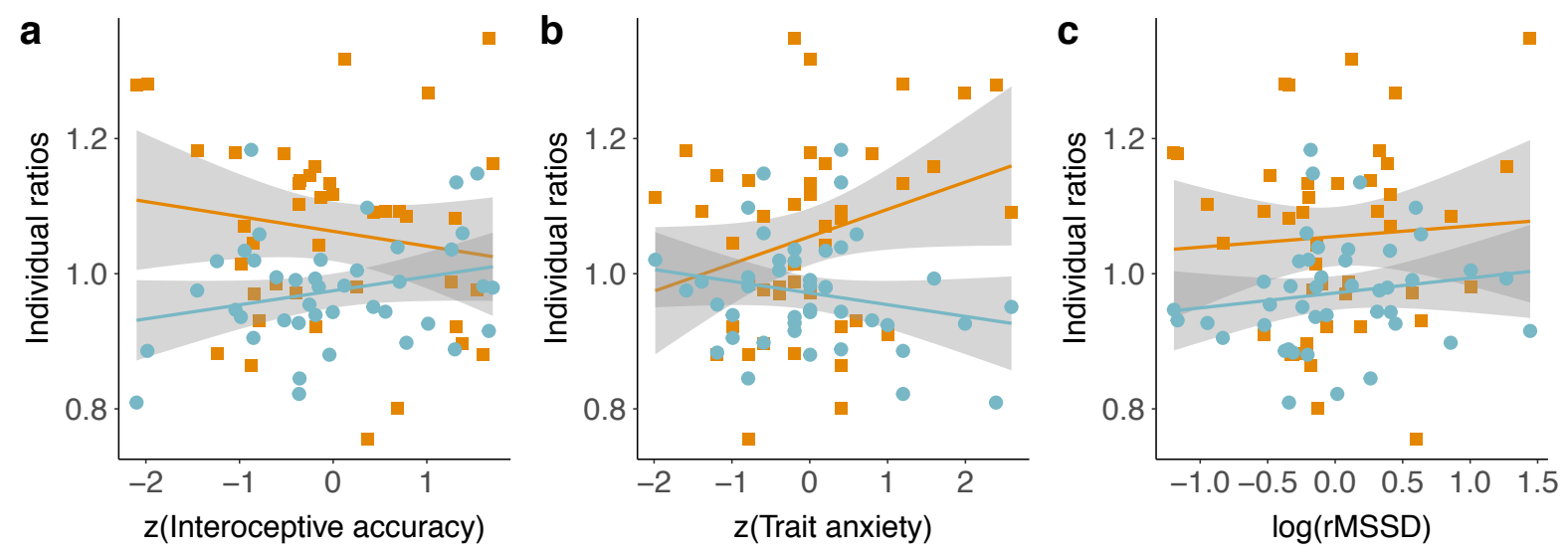

Figure 3. Correlation of systolic (orange squares) and diastolic (blue circles) ratios of picture onsets with inter-individual differences in $\boldsymbol{a}$, Interoceptive accuracy, $\boldsymbol{b}$, trait anxiety, and $\boldsymbol{c}$, resting heart rate variability (root mean square of successive differences, rMSSD). Grey areas are the $95 \%$ confidence intervals of the respective linear models (orange / blue lines).

Recognition memory varies and inter-individual differences. We furthermore investigated the role of inter-individual variables (i.e., interoceptive accuracy, trait anxiety, resting heart rate variability) for memory performance with correlation analyses. Neither differences in interoceptive accuracy $(r(39)=-.12, p=.46)$, nor in trait anxiety $(r(41)=.039, p=$ .80) were associated with mean recognition performance (Fig. 4). However, there was a nonsignificant trend of resting heart rate variability (i.e., resting rMSSD) to be positively correlated with mean recognition performance $(r(41)=.29, p=.056)$, that is, recognition memory increased with higher resting heart rate variability (Fig. 4c).
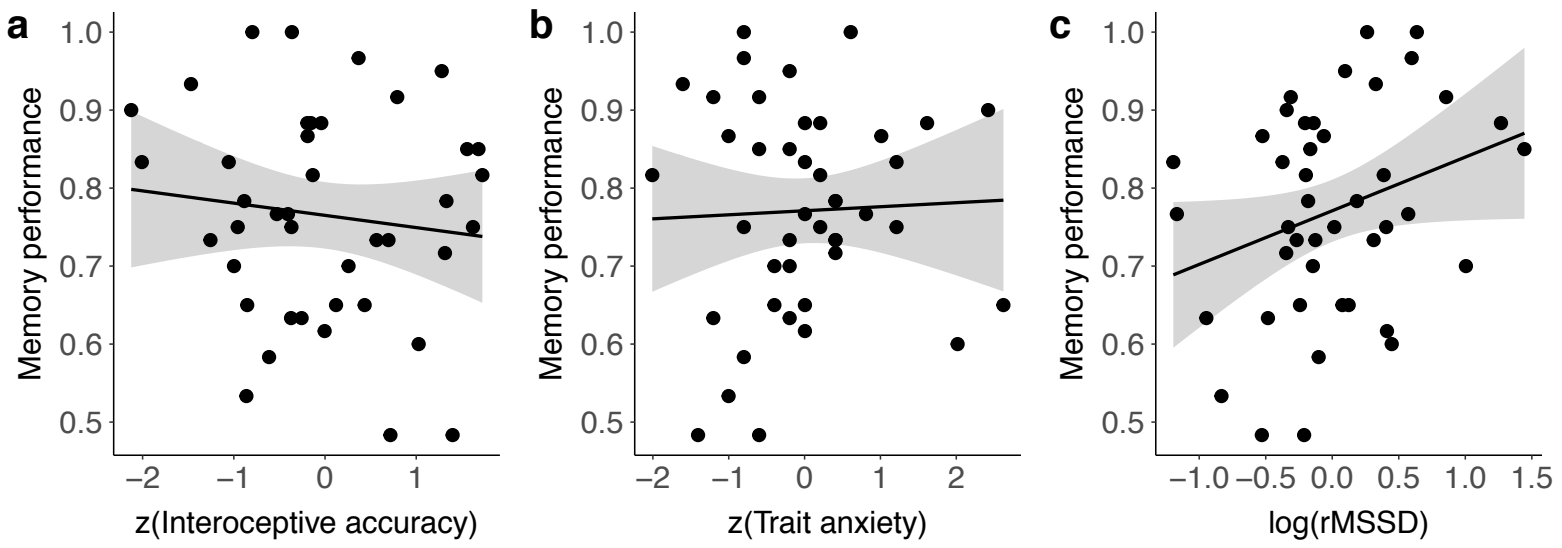
Figure 4. Correlation of mean recognition performance with inter-individual differences. $a$, interoceptive accuracy, $\boldsymbol{b}$, trait anxiety, and $\boldsymbol{c}$, resting heart rate variability (root mean square of successive differences, rMSSD). Grey areas are the $95 \%$ confidence intervals of the linear model (black line).

Subjective perception of picture emotionality. As a control, we analysed if the subjective valence and arousal ratings in our study differed from the EmoPicS normative ratings (Fig. 5). For ratings of the two affective dimensions, valence and arousal, mixeddesign ANOVAs tested the main and interaction effects of the repeated-measures factor rating category (normative, individual) and the factor picture valence (positive, neutral, negative). We observed a significant main effect of rating category for both, valence and arousal: Mean individual valence ratings $(M=5.06, S D=1.43)$ were significantly lower $(F(1,352)=$ $10.1, p=.002)$ than normative ratings $(M=5.23, S D=1.69)$, as were mean individual arousal ratings $(M=3.85, S D=1.09)$ compared to normative $(M=4.37, S D=1.28)$ ratings $(F(1,352)=27.0, p<.001)$. However, while valence ratings did not show a significant interaction for rating category $X$ picture valence $(F(2,352)=1.91, p=.15$; see Fig. 5a), the difference between individual and normative arousal ratings was influenced by picture valence $(F(2,352)=5.71, p=.004$; see Fig. 5b). To further examine this interaction, two-sided paired t-tests were calculated and $p$-values were adjusted for multiple comparisons with Bonferroni correction: positive (individual: $\mathrm{M}=4.04, \mathrm{SD}=0.65$; normative: $\mathrm{M}=4.90, \mathrm{SD}=0.58$ ) arousal ratings differed significantly larger from each other $(t(59)=20.2, p=<.001$, Cohen's $d=1.39)$ than both neutral (individual: $M=2.91, S D=0.34$; normative: $M=3.09, S D=0.32)(t(59)=4.77$, $p=<.001$, Cohen's $d=0.52$ ) and negative (individual: $M=4.60, S D=1.26$; normative: $M=5.13, S D=1.41)$ arousal ratings $(t(59)=9.32, p=<.001$, Cohen's $d=0.40)$. Furthermore, while normative arousal ratings did not differ significantly between positive and negative pictures (cf. Methods), individual arousal ratings were significantly higher for negative compared to positive pictures $(t(88.3)=3.05, p=.003$, Cohen's $d=0.56)$. 

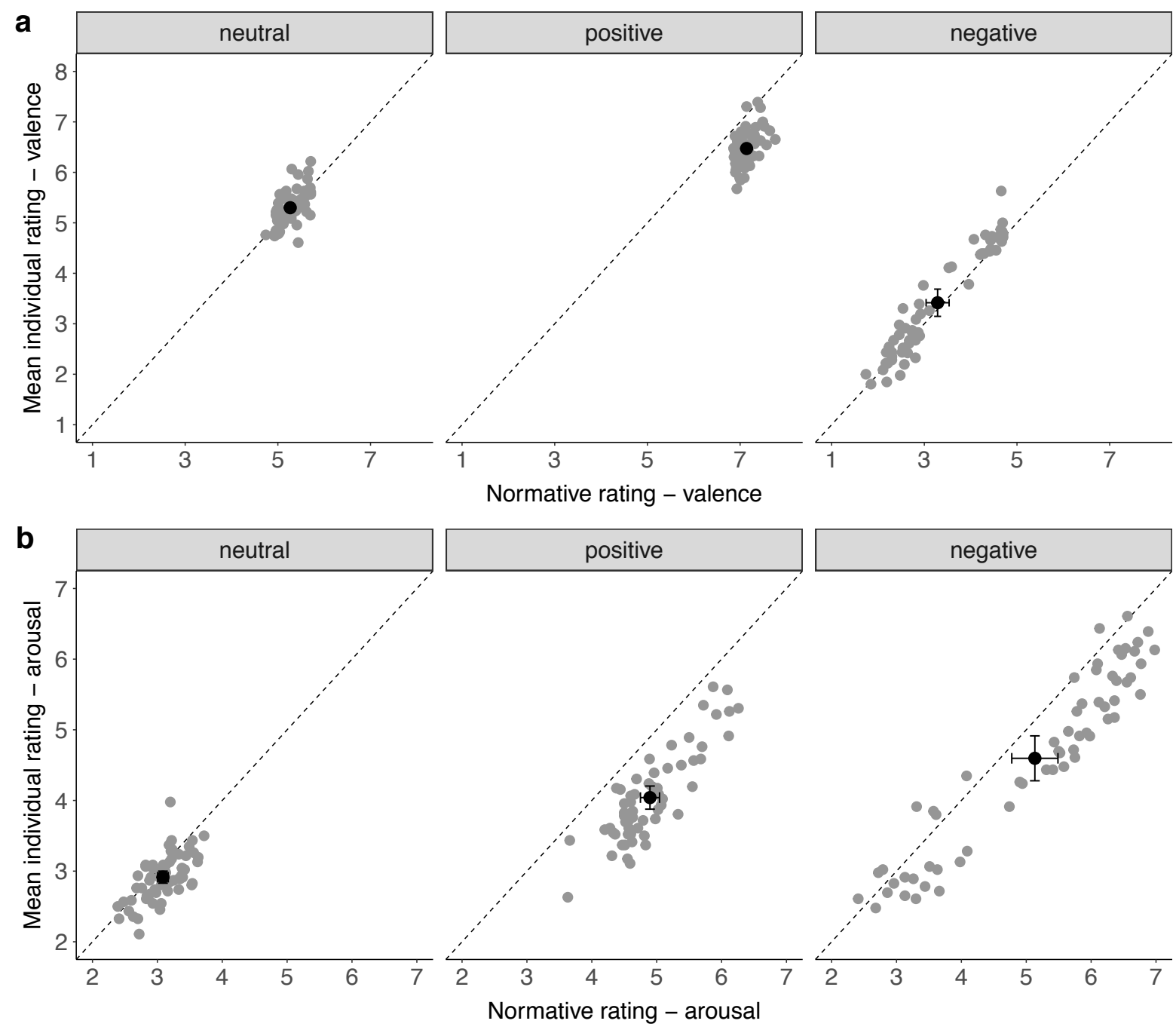

Figure 5. Subjective perception of picture emotionality (individual valence and arousal ratings)

compared to normative picture ratings. a, Valence ratings and $\boldsymbol{b}$, Arousal ratings were both significantly lower for individual compared to normative ratings (overall mean in black with standard error bars). For arousal but not for valence ratings there was a significant interaction effect between rating category and picture valence. 


\section{Discussion}

We studied the association between the cardiac cycle and self-paced visual sampling as well as visual recognition memory for pictures of different emotional valence. We hypothesized that facilitated visual processing (Pramme et al., 2014, 2016)_observed specifically for relevant or emotionally salient stimuli (Azevedo et al., 2018, 2017; Garfinkel et al., 2014)_as well as facilitated oculomotor processing during systole (Ohl et al., 2016) guides active perception in the shape of a preference to prompt a relevant visual stimulus during early phases of the cardiac cycle. We observed a significant accumulation of key presses (i.e., prompted picture onsets) during systole, thereby showing for the first time a coupling between selfpaced visual sampling and the heartbeat. Memory performance, however, was only influenced by picture valence, replicating a significant memory benefit for emotional content (Hamann, 2001; Kensinger, 2006; Kensinger \& Corkin, 2003; LaBar \& Cabeza, 2006), but not further modulated by the cardiac phase in which targets were encoded (Garfinkel et al., 2013). The association between the cardiac cycle and self-initiated actions complements findings of facilitated visual processing during systole, thereby proposing a link between the heartbeat and active perception.

Sensorimotor processing of passively presented stimuli has been shown to be decreased during early cardiac phases (Birren et al., 1963; Callaway \& Layne, 1964; Edwards et al., 2007; Lacey \& Lacey, 1974; Mclntyre et al., 2008; Saari \& Pappas, 1976), but evi-

511 dence is mixed, including some earlier null findings (Jennings \& Wood, 1977; Salzman \&

512 Jaques, 1976; Thompson \& Botwinick, 1970). However, which processing stages are modu-

513 lated by the heartbeat has long remained unclear. More fine-graded decomposition of reac-

514 tion time into central (sensory, pre-motor) and peripheral (motor) processes has indicated 515 that the response inhibition during early cardiac phases was confined to central (pre-motor) 516 levels of stimulus processing, whereas the motor component remained unaffected (Edwards 517 et al., 2007; Mclntyre et al., 2008; Saari \& Pappas, 1976) or even accelerated (Schulz et al., 518 2009). This differential effect could also underlie findings that report an increased tendency 519 to act during systole such as fire a virtual (Azevedo et al., 2017) or an actual weapon (Mets 
et al., 2007) during early cardiac phases. Our results of facilitated spontaneous actions dur-

ing systole when engaging with a visual stimulus furthermore add to results from oculomotor behaviour: Ohl et al. (2016) reported involuntarily occurring oculomotor activity (i.e., microsaccade generation) to be heightened during early cardiac phases. Hence, for both somatomotor and oculomotor processes, our readiness to act upon an external stimulus fluctuates with our (internal) cardiac rhythm, being relatively increased during the phase of systolic blood ejection.

Although underlying heart-brain pathways remain unclear, systolic influences on perception and cognition have often been attributed to the phasic nature of cardio-afferent signalling, which is triggered with the heartbeat (Koriath \& Lindholm, 1986; Lacey \& Lacey, 1974, 1978). More specifically, stretch-responsive baroreceptors located in arterial walls respond to transient pressure rises at each blood ejection and communicate the current cardiovascular state (i.e., the heartbeat's strength and timing) to the brain. Thus, baroreceptortransmitted cardiac signals, which are phasically registered by central processing systems, have been proposed to induce a general suppression of cortical excitability, converging with earlier findings of sensory inhibition (Dembowsky \& Seller, 1995; Rau \& Elbert, 2001). Formulated in terms of the interoceptive predictive coding framework (Barrett \& Simmons, 2015; Seth, 2013), which extends the free-energy principle (Friston, 2010) to interoceptive processes and connects them to consciousness and emotion, this periodic-and thus predicta-

539 ble-ascending baroreceptor input to central structures is anticipatorily cancelled out by top-

540 down interoceptive predictions, thereby minimizing its influence on perception (Critchley \&

541 Garfinkel, 2018; Salomon et al., 2016). Besides modulating arterial baroreceptor discharge,

542 heartbeat-related pressure fluctuations generate periodic sensory influences throughout the 543 body - affecting for example the discharge of tactile (Macefield, 2003) or muscle spindle af544 ferents (Birznieks, Boonstra, \& Macefield, 2012)—which are predicted and normally do not 545 enter perceptual awareness. In our constant attempt to minimize sensory uncertainty (Peters, 546 McEwen, \& Friston, 2017), inhibition of such predictable cardiac-induced sensory effects has 547 been argued to reduce-potentially distracting—self-related sensory noise (Salomon et al., 
2016) at the benefit of our processing of the outside world, for example by increasing the signal-to-noise ratio of external stimuli. Correspondingly, stimuli presented simultaneously with the heartbeat are interpreted as sensory consequences of the organism's own (internal) cardiac activity and thus perceptually attenuated (Salomon et al., 2016). Our finding that participants implicitly act upon a visual stimulus during the phase of heartbeat-related (baroreceptor-mediated) central inhibition could indicate a short-term benefit: As argued by Pramme et al. (2016), the impact of baroreceptor-mediated central influences may depend on contextor task-specific processing demands. In other words, extraction of behaviourally relevant external stimuli from a distracting sensory scene might be facilitated during inhibition of irrelevant (e.g., cardiac-related) sensory information (Pramme et al., 2016). Accordingly, predictable phases of attenuated heartbeat-related noise might provide a short-term window to facilitate active engagement towards an external relevant stimulus.

Such differential processing during transient cardiac signalling converges with the observed specificity of cardiac effects when using valenced stimuli, in particular selectively facilitated processing of threat stimuli during systole (Garfinkel \& Critchley, 2016). The notion that cardiac signals prioritise the processing of motivationally relevant information suggests a crucial role of cardiac interoceptive information in conveying bodily arousal states to the brain (Critchley \& Garfinkel, 2018; Garfinkel \& Critchley, 2016). In other studies, states of higher psychophysiological arousal have shown to bias the processing of relevant stimuli, including facilitated memory formation (Cahill \& McGaugh, 1998; Mather et al., 2016; Mather \& Sutherland, 2011; McGaugh, 2015). However, the pattern of results concerning memory modulation across the cardiac cycle remains fragmented and unclear. Although perceptual sensitivity for emotional stimuli is increased during systole (Garfinkel et al., 2014), affective (positive, negative) and neutral words are recalled less often when they are encoded during systole as compared to diastole (Garfinkel et al., 2013). Furthermore, this cardiac memory

573 effect could only be obtained in subjects with lower interoceptive accuracy, suggesting influ574 ences of an individual's access to interoceptive sensations (Pollatos \& Schandry, 2008). On 
systole are more likely to be judged as known or old, irrespective of whether they had been shown before or not. In our study, recognition memory was not influenced by the cardiac phase during which a stimulus was encoded-also adding to a recent study reporting a lack of cardiac influences on memory retrieval (Pfeifer et al., 2017)—but only by its valence, showing a significant benefit for negative and positive pictures. This suggests that-at least in our study - the influence of externally-induced emotional arousal states (e.g., by seeing an upsetting negative picture) on memory formation (Tambini et al., 2017) might have exceeded a transient cognitive modulation across the cardiac cycle (Garfinkel et al., 2013). Such reasoning is further supported by a recent study showing that interoceptive cardiac signals can easily be overshadowed by external stimuli or other task-specific influences (Yang, Jennings, \& Friedman, 2017). Although in our study, stimulus content was largely matched along several dimensions (physical image statistics and more high-level features), differences in stimulus features may still account for variation in memory effects associated with the cardiac cycle. For example, differences have been reported for different stimulus categories like words (Garfinkel et al., 2013), faces (Fiacconi et al., 2016), and complex scenes (present study), but also for low-level stimulus properties such as spatial frequency (Azevedo et al., 2018). However, accounting for picture as random effect in our GLMM analyses did not explain additional variance in memory performance across the cardiac cycle. Our exploratory supplementary finding indicates that inter-individual differences in recognition memory are positively associated with inter-individual differences in resting heart rate variability. Considered a trait marker of autonomic or parasympathetic cardio-regulation and-more generally—of heart-brain coupling (Thayer et al., 2012), variation in beat-to-beat intervals at rest has been associated with cognitive capacities: participants with higher resting heart rate variability performed better in tests of working memory and attention (Hansen, Johnsen, \& Thayer, 2003; Luft, Takase, \& Darby, 2009). Future studies investigating cardiac

601 influences on cognition could further examine the impact of inter-individual differences in 602 resting heart rate variability. 
Taken together, cardiac phase effects on perception, cognition, and behaviour might constitute a non-functional epiphenomenon emerging from transient physiological changes, which set the context for heart-brain interactions: As baroreceptor-transmitted afferent signals (Critchley \& Harrison, 2013) occur with every systolic pressure wave and reflect momentary states of increased blood pressure, they constitute a fine-tuned reference of cardiovascular arousal. Although autonomously generated, cardiac fluctuations are integrated in multiple feedback loops to react to environmental challenges such as exercise, body position, or stress (Dampney et al., 2002; Glass, 2001; Saper, 2002). Cardiovascular arousal is thus directly encoded via frequency (e.g., increased heart rate) and waveform (e.g., increased am-

612 plitude in elevated blood pressure) (Dampney et al., 2002; Schächinger, Weinbacher, Kiss, 613 Ritz, \& Langewitz, 2001), which reciprocally affect afferent baroreceptor stimulation 614 (Chapleau, Li, Meyrelles, Ma, \& Abboud, 2001). Influences of the cardiovascular state on sensory processing might thus subtly emerge with heartbeat-related pressure fluctuations, but are only fully expressed under a sustained shift of our bodily state beyond physiological variability; for example, under stress, when the whole spectrum of adaptive brain-body responses is activated (e.g., elevated blood pressure and accelerated heart rate) and the afferent cardiac signalling increases. Correspondingly, Luft and Bhattacharya (2015) found that the representation of cardiac signals in the brain, as measured by EEG-derived heartbeatevoked potentials, differs between states of high vs. low emotional arousal. Besides increased amplitudes in arterial pressure waves, it could be argued that a faster heartbeat during stressful situations-next to providing metabolic support for action requirements to restabilize our homeostatic integrity (Gianaros \& Wager, 2015)—results in relatively increased systolic signalling (as raises in heart rate occur mainly at the expense of diastole length) and thereby generates more time windows of selectively facilitated sensory processing. Evidence for this proposal comes from a recent study that associated experimentally increased heart rates (Pezzulo et al., 2018) with prioritized fear processing across different measures (reac-

629 tion time, peak velocity, response acceleration, choice uncertainty). Hence, increased signal-

630 ling of cardiovascular states under conditions of higher bodily arousal and heart rates might 
more strongly modulate cognition and behaviour (e.g., active perception and self-paced action), thereby supporting what information is preferentially processed.

Our experiment has several limitations: While linking active perception and the cardiac cycle, our design does not allow to decompose cardiac influences at the levels of somatomotor, sensory, and cognitive processing. A control condition to dissociate cardiac-related motor activity from visual processing could rule out a pure motor effect, for example by testing spontaneous motor actions that are not explicitly coupled to perception of (relevant) stimuli. The hypothesis would be that button presses that do not prompt relevant sensory input would be randomly (i.e., uniformly) distributed across the cardiac cycle. An essential step to investigate the role of cardiac activity as bodily reference would be to test cardiac coupling of stimulus processing under conditions of altered cardiac activity (e.g., increased heart rate), for example by inducing stress through increased sensory uncertainty (e.g., by manipulating stimulus predictability). In addition, measurements of cardiac representations in the brain (e.g., using EEG) would extend our understanding of the central integration and modulation of cardiac signals, for example, in the context of self-paced visual sampling and visual memory processing.

In conclusion, our findings imply that the heartbeat constitutes a crucial bodily signal that is integrated in our active engagement with the external world. Specifically, they suggest that we tend to act in a phase of inhibited cardiac- and thus self-related sensory processing (namely cardiac systole) when extracting relevant information from our environment. Subtly emerging under normal conditions, this influence might become functionally relevant in states of high arousal (e.g., in stressful situations). Extending previous frameworks of mind-brainbody interactions (Park \& Tallon-Baudry, 2014), we propose that we implicitly exploit internal ongoing bodily fluctuations as a predictable reference frame from which interaction with our ever-changing and often unpredictable environment can arise. When initiating actions to

656 sample the noisy world around us, we relate them to the rhythm we know best-our own 657 heartbeat. 


\section{References.}

659

660

661

662

663

664

665

666

667

668

669

670

671

672

673

674

675

676

677

678

679

680

681

682

683

684

685

686

687

688

689

690

691

692

693

694

695

696

697

698

699

700

701

702

703

Agostinelli, C., \& Lund, U. (2013). R package "circular": Circular Statistics (version 0.4-7). CA: Department of Environmental Sciences, Informatics and Statistics, Ca' Foscari University, Venice, Italy. UL: Department of Statistics, California Polytechnic State University, San Luis Obispo, California, USA. Retrieved from https://r-forge.rproject.org/projects/circular/

Angell James, J. E. (1971). The effects of altering mean pressure, pulse pressure and pulse frequency on the impulse activity in baroreceptor fibres from the aortic arch and right subclavian artery in the rabbit. The Journal of Physiology, 214(1), 65-88. https://doi.org/10.1113/jphysiol.1971.sp009419

Azevedo, R. T., Badoud, D., \& Tsakiris, M. (2018). Afferent cardiac signals modulate attentional engagement to low spatial frequency fearful faces. Cortex, 104(July), 232240. https://doi.org/10.1016/J.CORTEX.2017.06.016

Azevedo, R. T., Garfinkel, S. N., Critchley, H. D., \& Tsakiris, M. (2017). Cardiac afferent activity modulates the expression of racial stereotypes. Nature Communications, 8 , 13854. https://doi.org/10.1038/ncomms 13854

Barrett, L. F., \& Simmons, W. K. (2015). Interoceptive predictions in the brain. Nature Reviews Neuroscience, 16(7), 419-429. https://doi.org/10.1038/nrn3950

Bates, D., Mächler, M., Bolker, B., \& Walker, S. (2015). Fitting Linear Mixed-Effects Models using Ime4. Journal of Statistical Software, 67(1), 1-48. https://doi.org/10.18637/jss.v067.i01

Benedetto, A., Spinelli, D., \& Morrone, M. C. (2016). Rhythmic modulation of visual contrast discrimination triggered by action. Proceedings of the Royal Society B: Biological Sciences, 283(1831), 20160692. https://doi.org/10.1098/rspb.2016.0692

Birren, J. E., Cardon, P. V, \& Phillips, S. L. (1963). Reaction Time as a Function of the Cardiac Cycle in Young Adults. Science, 140(3563), 195-196. Retrieved from http://science.sciencemag.org/content/140/3563/195.2.abstract

Birznieks, I., Boonstra, T. W., \& Macefield, V. G. (2012). Modulation of human muscle spindle discharge by arterial pulsations - functional effects and consequences. PLoS ONE, 7(4), e35091. https://doi.org/10.1371/journal.pone.0035091

Brainard, D. H. (1997). The Psychophysics Toolbox. Spatial Vision, 10(4), 433-436. https://doi.org/10.1163/156856897X00357

Cahill, L., \& McGaugh, J. L. (1998). Mechanisms of emotional arousal and lasting declarative memory. Trends in Neurosciences, 21(7), 294-299. Retrieved from https://doi.org/10.1016/S0166-2236(97)01214-9

Callaway, E., \& Layne, R. S. (1964). Interaction between the visual evoked response and two spontaneous biological rhythms: the EEG alpha cycle and the cardiac arousal cycle. Annals of the New York Academy of Sciences, 112(1), 421-431. https://doi.org/10.1111/j.1749-6632.1964.tb26762.x

Chapleau, M. W., Li, Z., Meyrelles, S. S., Ma, X., \& Abboud, F. M. (2001). Mechanisms determining sensitivity of baroreceptor afferents in health and disease. Annals of the New York Academy of Sciences, 940(1), 1-19. https://doi.org/10.1111/j.17496632.2001.tb03662.x

Craig, A. D. B. (2002). How do you feel? Interoception: the sense of the physiological condition of the body. Nature Reviews Neuroscience, 3(8), 655-666. https://doi.org/10.1038/nrn894 
Critchley, H. D., \& Garfinkel, S. N. (2018). The influence of physiological signals on cognition. Current Opinion in Behavioral Sciences, 19, 13-18. https://doi.org/10.1016/j.cobeha.2017.08.014

Critchley, H. D., \& Harrison, N. A. (2013). Visceral Influences on Brain and Behavior. Neuron, 77(4), 624-638. https://doi.org/10.1016/j.neuron.2013.02.008

Dampney, R. A. L., Coleman, M. J., Fontes, M. A. P., Hirooka, Y., Horiuchi, J., Li, Y.-W. W., ... Tagawa, T. (2002). Central mechanisms underlying short- and long-term regulation of the cardiovascular system. Clinical and Experimental Pharmacology \& Physiology, 29(4), 261-268. https://doi.org/10.1046/j.1440-1681.2002.03640.x

Dembowsky, K., \& Seller, H. (1995). Arterial baroreceptor reflexes. In D. Vaitl \& R. Schandry (Eds.), From the Heart to the Brain: The Psychophysiology of Circulation-Brain Interaction. (pp. 35-60). Europäischer Verlag der Wissenschaften Frankfurt aM.

Deubel, H., \& Schneider, W. X. (1996). Saccade target selection and object recognition: Evidence for a common attentional mechanism. Vision Research, 36(12), 1827-1837. https://doi.org/10.1016/0042-6989(95)00294-4

Dunn, B. D., Galton, H. C., Morgan, R., Evans, D., Oliver, C., Meyer, M., ... Dalgleish, T. (2010). Listening to your heart: How interoception shapes emotion experience and intuitive decision making. Psychological Science, 21(12), 1835-1844. https://doi.org/10.1177/0956797610389191

Edwards, L., Mclntyre, D., Carroll, D., Ring, C., \& Martin, U. (2002). The human nociceptive flexion reflex threshold is higher during systole than diastole. Psychophysiology, 39(5), 678-681. https://doi.org/10.1017/S0048577202011770

Edwards, L., Ring, C., McIntyre, D., Carroll, D., \& Martin, U. (2007). Psychomotor speed in hypertension: Effects of reaction time components, stimulus modality, and phase of the cardiac cycle. Psychophysiology, 44(3), 459-468. https://doi.org/10.1111/j.14698986.2007.00521.x

Fan, J., Xu, P., Van Dam, N. T., Eilam-Stock, T., Gu, X., Luo, Y. J., \& Hof, P. R. (2012). Spontaneous brain activity relates to autonomic arousal. Journal of Neuroscience, 32(33), 11176-11186. https://doi.org/10.1523/JNEUROSCI.1172-12.2012

Fiacconi, C. M., Peter, E. L., Owais, S., \& Köhler, S. (2016). Knowing by heart: Visceral feedback shapes recognition memory judgments. Journal of Experimental Psychology, 145(5), 559-572. https://doi.org/10.1037/xge0000164

Fridericia, L. S. (1920). Die Systolendauer im Elektrokardiogramm bei normalen Menschen und bei Herzkranken. Journal of Internal Medicine, 53(1), 469-486. https://doi.org/10.1111/j.0954-6820.1920.tb18266.x

Friston, K. (2010). The free-energy principle: A unified brain theory? Nature Reviews Neuroscience, 11(2), 127-138. https://doi.org/10.1038/nrn2787

Garfinkel, S. N., Barrett, A. B., Minati, L., Dolan, R. J., Seth, A. K., \& Critchley, H. D. (2013). What the heart forgets: Cardiac timing influences memory for words and is modulated by metacognition and interoceptive sensitivity. Psychophysiology, 50(6), 505-512. https://doi.org/10.1111/psyp.12039

Garfinkel, S. N., \& Critchley, H. D. (2016). Threat and the Body: How the Heart Supports Fear Processing. Trends in Cognitive Sciences, 20(1), 34-46. https://doi.org/10.1016/j.tics.2015.10.005

Garfinkel, S. N., Minati, L., Gray, M. A., Seth, A. K., Dolan, R. J., \& Critchley, H. D. (2014). Fear from the Heart: Sensitivity to Fear Stimuli Depends on Individual Heartbeats. Journal of Neuroscience, 34(19), 6573-6582. 
https://doi.org/10.1523/JNEUROSCI.3507-13.2014

Gianaros, P. J., \& Wager, T. D. (2015). Brain-Body Pathways Linking Psychological Stress and Physical Health. Current Directions in Psychological Science, 24(4), 313-321. https://doi.org/10.1177/0963721415581476

Glass, L. (2001). Synchronization and rhythmic processes in physiology. Nature, 410(6825), 277-284. https://doi.org/10.1038/35065745

Greiner, B. (2015). Subject pool recruitment procedures: organizing experiments with ORSEE. Journal of the Economic Science Association, 1(1), 114-125. https://doi.org/10.1007/s40881-015-0004-4

Hamann, S. (2001). Cognitive and neural mechanisms of emotional memory. Trends in Cognitive Sciences, 5(9), 394-400. https://doi.org/10.1016/S1364-6613(00)01707-1

Hanning, N. M., Jonikaitis, D., Deubel, H., \& Szinte, M. (2016). Oculomotor selection underlies feature retention in visual working memory. Journal of Neurophysiology, 115(2), 1071-1076. https://doi.org/10.1152/jn.00927.2015

Hansen, A. L., Johnsen, B. H., \& Thayer, J. F. (2003). Vagal influence on working memory and attention. International Journal of Psychophysiology, 48(3), 263-274. https://doi.org/10.1016/S0167-8760(03)00073-4

Hogendoorn, H. (2016). Voluntary Saccadic Eye Movements Ride the Attentional Rhythm. Journal of Cognitive Neuroscience, 28(10), 1625-1635. https://doi.org/10.1162/jocn_a_00986

Jaeger, T. F. (2008). Categorical Data Analysis: Away from ANOVAs (transformation or not) and towards Logit Mixed Models. Journal of Memory and Language, 59(4), 434-446. https://doi.org/10.1016/j.jml.2007.11.007

Jennings, J. R., \& Wood, C. C. (1977). Cardiac Cycle Time Effects on Performance, Phasic Cardiac Responses, and Their Intercorrelation in Choice Reaction Time. Psychophysiology, 14(3), 297-307. https://doi.org/10.1111/j.1469-8986.1977.tb01179.x

Kensinger, E. A. (2006). Amygdala Activity Is Associated with the Successful Encoding of Item, But Not Source, Information for Positive and Negative Stimuli. Journal of Neuroscience, 26(9), 2564-2570. https://doi.org/10.1523/JNEUROSCI.5241-05.2006

Kensinger, E. A., \& Corkin, S. (2003). Memory enhancement for emotional words: Are emotional words more vividly remembered than neutral words? Memory \& Cognition, 31(8), 1169-1180. https://doi.org/10.3758/BF03195800

Kleckner, I. R., Zhang, J., Touroutoglou, A., Chanes, L., Xia, C., Simmons, W. K., ... Feldman Barrett, L. (2017). Evidence for a large-scale brain system supporting allostasis and interoception in humans. Nature Human Behaviour, 1(5), 69. https://doi.org/10.1038/s41562-017-0069

Kleiner, M., Brainard, D., Pelli, D., Ingling, A., Murray, R., \& Broussard, C. (2007). What's new in Psychtoolbox-3? Perception, 36(14), 1-16. Retrieved from https://nyuscholars.nyu.edu/en/publications/whats-new-in-psychtoolbox-3

Koriath, J. J., \& Lindholm, E. (1986). Cardiac-related cortical inhibition during a fixed foreperiod reaction time task. International Journal of Psychophysiology, 4(3), 183-195. https://doi.org/10.1016/0167-8760(86)90014-0

Kowler, E., Anderson, E., Dosher, B., \& Blaser, E. (1995). The role of attention in the programming of saccades. Vision Research, 35(13), 1897-1916. https://doi.org/10.1016/0042-6989(94)00279-U

LaBar, K. S., \& Cabeza, R. (2006). Cognitive neuroscience of emotional memory. Nature 
Reviews Neuroscience, 7(1), 54-64. https://doi.org/10.1038/nrn1825

Lacey, B. C., \& Lacey, J. I. (1974). Studies of heart rate and other bodily processes in sensorimotor behavior. In P. A. Obrist, A. H. Black, J. Brener, \& L. V. DiCara (Eds.), Cardiovascular psychophysiology: Current issues in response mechanisms, biofeedback and methodology. (pp. 538-564). New Brunswick, NJ, US: AldineTransaction. Retrieved from http://psycnet.apa.org/record/2007-11499-026

Lacey, B. C., \& Lacey, J. I. (1978). Two-way communication between the heart and the brain. Significance of time within the cardiac cycle. American Psychologist, 33(2), 99-113. https://doi.org/10.1037/0003-066X.33.2.99

Laux, L., Glanzmann, P., Schaffner, P., \& Spielberger, C. D. (1981). State-Trait Anxiety Inventory (Spielberger, C.D., Gorsuch, R.L., Lushene, R.E., 1970) - Deutsche Version. Das State Trait Angstinventar (Testmappe mit Handanweisung, Fragebogen STAI G Form $X 1$ und Fragebogen STAI G Form X 2). Weinheim: Beltz.

Lewis, R. P., Rittogers, S. E., Froester, W. F., \& Boudoulas, H. (1977). A critical review of the systolic time intervals. Circulation, 56(2), 146-158. https://doi.org/10.1161/01.CIR.56.2.146

Li, H. H., Barbot, A., \& Carrasco, M. (2016). Saccade Preparation Reshapes Sensory Tuning. Current Biology, 26(12), 1564-1570. https://doi.org/10.1016/j.cub.2016.04.028

Lombard, W. P., \& Cope, O. M. (1926). The duration of the systole of the left ventricle of man. American Journal of Physiology--Legacy Content, 77(2), 263-295. Retrieved from https://doi.org/10.1152/ajplegacy.1926.77.2.263

Luft, C. D. B., \& Bhattacharya, J. (2015). Aroused with heart: Modulation of heartbeat evoked potential by arousal induction and its oscillatory correlates. Scientific Reports, 5(1), 15717. https://doi.org/10.1038/srep15717

Luft, C. D. B., Takase, E., \& Darby, D. (2009). Heart rate variability and cognitive function: Effects of physical effort. Biological Psychology, 82(2), 196-201. https://doi.org/10.1016/j.biopsycho.2009.07.007

Macefield, V. G. (2003). Cardiovascular and respiratory modulation of tactile afferents in the human finger pad. Experimental Physiology, 88(5), 617-625. https://doi.org/10.1113/eph8802548

Mather, M., Clewett, D., Sakaki, M., \& Harley, C. W. (2016). Norepinephrine ignites local hotspots of neuronal excitation: How arousal amplifies selectivity in perception and memory. Behavioral and Brain Sciences, 39, 1-75. https://doi.org/10.1017/S0140525X15000667

Mather, M., \& Sutherland, M. R. (2011). Arousal-biased competition in perception and memory. Perspectives on Psychological Science, 6(2), 114-133. https://doi.org/10.1177/1745691611400234

Mayer, E. A. (2011). Gut feelings: The emerging biology of gut-brain communication. Nature Reviews Neuroscience, 12(8), 453-466. https://doi.org/10.1038/nrn3071

McGaugh, J. L. (2015). Consolidating Memories. Annual Review of Psychology, 66(1), 1-24. https://doi.org/10.1146/annurev-psych-010814-014954

Mclntyre, D., Ring, C., Edwards, L., \& Carroll, D. (2008). Simple reaction time as a function of the phase of the cardiac cycle in young adults at risk for hypertension. Psychophysiology, 45(2), 333-336. https://doi.org/10.1111/j.1469-8986.2007.00619.x

Merrikhi, Y., Clark, K., Albarran, E., Parsa, M., Zirnsak, M., Moore, T., \& Noudoost, B. (2017). Spatial working memory alters the efficacy of input to visual cortex. Nature 
Communications, 8, 15041. https://doi.org/10.1038/ncomms15041

Mets, T., Konttinen, N., \& Lyytinen, H. (2007). Shot placement within cardiac cycle in junior elite rifle shooters. Psychology of Sport and Exercise, 8(2), 169-177. https://doi.org/10.1016/j.psychsport.2006.02.002

Moore, T., Tolias, A. S., \& Schiller, P. H. (1998). Visual representations during saccadic eye movements. Proceedings of the National Academy of Sciences, 95(15), 8981-8984. Retrieved from http://www.ncbi.nlm.nih.gov/entrez/query.fcgi?cmd=Retrieve\&db=PubMed\&dopt=Citatio n\&list_uids $=9671790$

Morillon, B., Schroeder, C. E., \& Wyart, V. (2014). Motor contributions to the temporal precision of auditory attention. Nature Communications, 5, 5255. https://doi.org/10.1038/ncomms6255

Ohl, S., Kuper, C., \& Rolfs, M. (2017). Selective enhancement of orientation tuning before saccades. Journal of Vision, 17(13), 1-11. https://doi.org/10.1167/17.13.2

Ohl, S., \& Rolfs, M. (2017). Saccadic eye movements impose a natural bottleneck on visual short-term memory. Journal of Experimental Psychology: Learning, Memory, and Cognition, 43(5), 736-748. https://doi.org/10.1037/xIm0000338

Ohl, S., Wohltat, C., Kliegl, R., Pollatos, O., \& Engbert, R. (2016). Microsaccades Are Coupled to Heartbeat. Journal of Neuroscience, 36(4), 1237-1241. https://doi.org/10.1523/JNEUROSCI.2211-15.2016

Park, H.-D., \& Tallon-Baudry, C. (2014). The neural subjective frame: from bodily signals to perceptual consciousness. Philosophical Transactions of the Royal Society B: Biological Sciences, 369(1641), 20130208-20130208. https://doi.org/10.1098/rstb.2013.0208

Pelli, D. G. (1997). The VideoToolbox software for visual psychophysics: Transforming numbers into movies. Spatial Vision, 10(4), 437-442. https://doi.org/10.1163/156856897X00366

Peters, A., McEwen, B. S., \& Friston, K. J. (2017). Uncertainty and stress: Why it causes diseases and how it is mastered by the brain. Progress in Neurobiology, 156, 164-188. https://doi.org/10.1016/j.pneurobio.2017.05.004

Pewsey, A., Neuhäuser, M., \& Ruxton, G. D. (2013). Circular Statistics in R. Oxford University Press. Retrieved from https://global.oup.com/academic/product/circularstatistics-in-r-9780199671137?cc=de\&lang=en\&

Pezzulo, G., lodice, P., Barca, L., Chausse, P., Monceau, S., \& Mermillod, M. (2018). Increased heart rate after exercise facilitates the processing of fearful but not disgusted faces. Scientific Reports, 8(1), 398. https://doi.org/10.1038/s41598-017-18761-5

Pfeifer, G., Garfinkel, S. N., Gould van Praag, C. D., Sahota, K., Betka, S., \& Critchley, H. D. (2017). Feedback from the heart: Emotional learning and memory is controlled by cardiac cycle, interoceptive accuracy and personality. Biological Psychology, 126, 1929. https://doi.org/10.1016/j.biopsycho.2017.04.001

Pikovsky, A., Rosenblum, M., \& Kurths, J. (2001). Synchronization: A Universal Concept in Nonlinear Sciences (1st ed.). Cambridge: Cambridge University Press. Retrieved from http://www.fulviofrisone.com/attachments/article/412/synchronization an universal concept in nonlinear sciences.pdf

Pollatos, O., \& Schandry, R. (2008). Emotional processing and emotional memory are modulated by interoceptive awareness. Cognition and Emotion, 22(2), 272-287. https://doi.org/10.1080/02699930701357535 
889

890

891

892

893

894

895

896

897

898

899

900

901

902

903

904

905

906

907

908

909

910

911

912

913

914

915

916

917

918

919

920

921

922

923

924

925

926

927

928

929

930

931

932

933

934

Pollatos, O., Schandry, R., Auer, D. P., \& Kaufmann, C. (2007). Brain structures mediating cardiovascular arousal and interoceptive awareness. Brain Research, 1141, 178-187. https://doi.org/10.1016/j.brainres.2007.01.026

Pramme, L., Larra, M. F., Schächinger, H., \& Frings, C. (2014). Cardiac cycle time effects on mask inhibition. Biological Psychology, 100(1), 115-121. https://doi.org/10.1016/j.biopsycho.2014.05.008

Pramme, L., Larra, M. F., Schächinger, H., \& Frings, C. (2016). Cardiac cycle time effects on selection efficiency in vision. Psychophysiology, 53(11), 1702-1711. https://doi.org/10.1111/psyp.12728

Rau, H., \& Elbert, T. (2001). Psychophysiology of arterial baroreceptors and the etiology of hypertension. Biological Psychology, 57(1-3), 179-201. https://doi.org/10.1016/S03010511(01)00094-1

Réquin, J., \& Brouchon, M. (1964). Mise en évidence chez l' homme d'une fluctuation des seuils perceptifs visuels dans la période cardiaque. Comptes Rendus Des Séances de La Société de Biologie et de Ses Filiales, 158, 1891-1894.

Richter, C. G., Babo-Rebelo, M., Schwartz, D., \& Tallon-Baudry, C. (2017). Phase-amplitude coupling at the organism level: The amplitude of spontaneous alpha rhythm fluctuations varies with the phase of the infra-slow gastric basal rhythm. Neurolmage, 146, 951-958. https://doi.org/10.1016/j.neuroimage.2016.08.043

RStudio Team. (2016). RStudio: Integrated Development Environment for R. Boston, MA: RStudio, Inc. Retrieved from http://www.rstudio.com/

Saari, M. J., \& Pappas, B. A. (1976). Cardiac cycle phase and movement and reaction times. Perceptual and Motor Skills, 42(3), 767-770. Retrieved from http://dx.doi.org/10.2466/pms.1976.42.3.767

Salomon, R., Ronchi, R., Dönz, J., Bello-Ruiz, J., Herbelin, B., Martet, R., ... Blanke, O. (2016). The Insula Mediates Access to Awareness of Visual Stimuli Presented Synchronously to the Heartbeat. Journal of Neuroscience, 36(18), 5115-5127. https://doi.org/10.1523/JNEUROSCI.4262-15.2016

Salzman, L. F., \& Jaques, N. (1976). Heart Rate and Cardiac Cycle Effects on Reaction Time. Perceptual and Motor Skills, 42(3_suppl), 1315-1321. https://doi.org/10.2466/pms.1976.42.3c. 1315

Sandman, C. A., McCanne, T. R., Kaiser, D. N., \& Diamond, B. (1977). Heart rate and cardiac phase influences on visual perception. Journal of Comparative and Physiological Psychology, 91(1), 189-202. Retrieved from https://www.ncbi.nlm.nih.gov/pubmed/838914

Saper, C. B. (2002). The Central Autonomic Nervous System: Conscious Visceral Perception and Autonomic Pattern Generation. Annual Review of Neuroscience, 25, 433-469. https://doi.org/10.1146/annurev.neuro.25.032502.111311

Schächinger, H., Weinbacher, M., Kiss, A., Ritz, R., \& Langewitz, W. (2001). Cardiovascular indices of peripheral and central sympathetic activation. Psychosomatic Medicine, 63(5), 788-796. https://doi.org/10.1097/00006842-200109000-00012

Schäfer, G., Rosenblum, M. G., Kurths, J., \& Abel, H. H. (1998). Heartbeat synchronized with ventilation. Nature, 392(6673), 239-240. https://doi.org/10.1038/32567

Schandry, R. (1981). Heart Beat Perception and Emotional Experience. Psychophysiology, 18(4), 483-488. https://doi.org/10.1111/j.1469-8986.1981.tb02486.x

Schulz, A., Reichert, C. F., Richter, S., Lass-Hennemann, J., Blumenthal, T. D., \& 
Schächinger, H. (2009). Cardiac modulation of startle: Effects on eye blink and higher cognitive processing. Brain and Cognition, 71(3), 265-271.

https://doi.org/10.1016/j.bandc.2009.08.002

Seth, A. K. (2013). Interoceptive inference, emotion, and the embodied self. Trends in Cognitive Sciences, 17(11), 565-573. https://doi.org/10.1016/j.tics.2013.09.007

Spielberger, C. D., Gorsuch, R. L., Lushene, P. R., Vagg, P. R., \& Jacobs, A. G. (1983). Manual for the State-Trait Anxiety Inventory (Form Y). Palo Alto, CA: Consulting Psychologists Press. https://doi.org/10.1007/978-1-4419-9893-4

Tambini, A., Rimmele, U., Phelps, E. A., \& Davachi, L. (2017). Emotional brain states carry over and enhance future memory formation. Nature Neuroscience, 20(2), 271-278. https://doi.org/10.1038/nn.4468

Tarvainen, M. P., Niskanen, J.-P., Lipponen, J. A., Ranta-aho, P. O., \& Karjalainen, P. A. (2014). Kubios HRV - Heart rate variability analysis software. Computer Methods and Programs in Biomedicine, 113(1), 210-220. https://doi.org/10.1016/j.cmpb.2013.07.024

Task Force of the European Society of Cardiology and the North American Society of Pacing and Electrophysiology (1996). Heart rate variability; Standards of measurements, physiological interpretation and clinical use. (1996). Circulation, 93, 1043-1065. Retrieved from http://circ.ahajournals.org/content/93/5/1043.abstract

Thayer, J. F., Åhs, F., Fredrikson, M., Sollers, J. J., \& Wager, T. D. (2012). A meta-analysis of heart rate variability and neuroimaging studies: Implications for heart rate variability as a marker of stress and health. Neuroscience and Biobehavioral Reviews, 36(2), 747756. https://doi.org/10.1016/j.neubiorev.2011.11.009

Thompson, L. W., \& Botwinick, J. (1970). Stimulation in different phases of the cardiac cycle and reaction time. Psychophysiology, 7(1), 57-65. https://doi.org/10.1111/j.14698986.1970.tb02276.x

Tomassini, A., Spinelli, D., Jacono, M., Sandini, G., \& Morrone, M. C. (2015). Rhythmic Oscillations of Visual Contrast Sensitivity Synchronized with Action. Journal of Neuroscience, 35(18), 7019-7029. https://doi.org/10.1523/JNEUROSCI.4568-14.2015

Tukey, J. W. (1977). Exploratory data analysis. Reading, MA: Addison-Wesley.

Wallace, A. G., Mitchell, J. H., Skinner, N. S., \& Sarnoff, S. J. (1963). Duration of the Phases of Left Ventricular Systole. Circulation Research, 12(6), 611-619. https://doi.org/10.1161/01.RES.12.6.611

Weissler, A. M., Harris, W. S., \& Schoenfield, C. D. (1968). Systolic Time Intervals in Heart Failure in Man. Circulation, 37(2), 149-159. Retrieved from http://circ.ahajournals.org/cgi/content/abstract/37/2/149

Wessa, M., Kanske, P., Neumeister, P., Bode, K., Heissler, J., \& Schönfelder, S. (2010). EmoPics: Subjektive und psychophysiologische Evaluation neuen Bildmaterials für die klinisch-biopsychologische Forschung. Zeitschrift Für Klinische Psychologie Und Psychotherapie, 39(Suppl. 1/11), 77.

Wickham, H. (2009). ggplot2: Elegant Graphics for Data Analysis. Springer-Verlag New York. Retrieved from http://ggplot2.org

Wilkinson, M., McIntyre, D., \& Edwards, L. (2013). Electrocutaneous pain thresholds are higher during systole than diastole. Biological Psychology, 94(1), 71-73. https://doi.org/10.1016/j.biopsycho.2013.05.002

Yang, X., Jennings, J. R., \& Friedman, B. H. (2017). Exteroceptive stimuli override interoceptive state in reaction time control. Psychophysiology, 54(12), 1940-1950. 
bioRxiv preprint doi: https://doi.org/10.1101/283838; this version posted January 26, 2019. The copyright holder for this preprint (which was not certified by peer review) is the author/funder, who has granted bioRxiv a license to display the preprint in perpetuity. It is made available under aCC-BY-NC-ND 4.0 International license.

https://doi.org/10.1111/psyp.12958

982

Zelano, C., Jiang, H., Zhou, G., Arora, N., Schuele, S., Rosenow, J., \& Gottfried, J. A. (2016).

983

Nasal Respiration Entrains Human Limbic Oscillations and Modulates Cognitive

984

Function. Journal of Neuroscience, 36(49), 12448-12467.

985

https://doi.org/10.1523/JNEUROSCI.2586-16.2016

986 